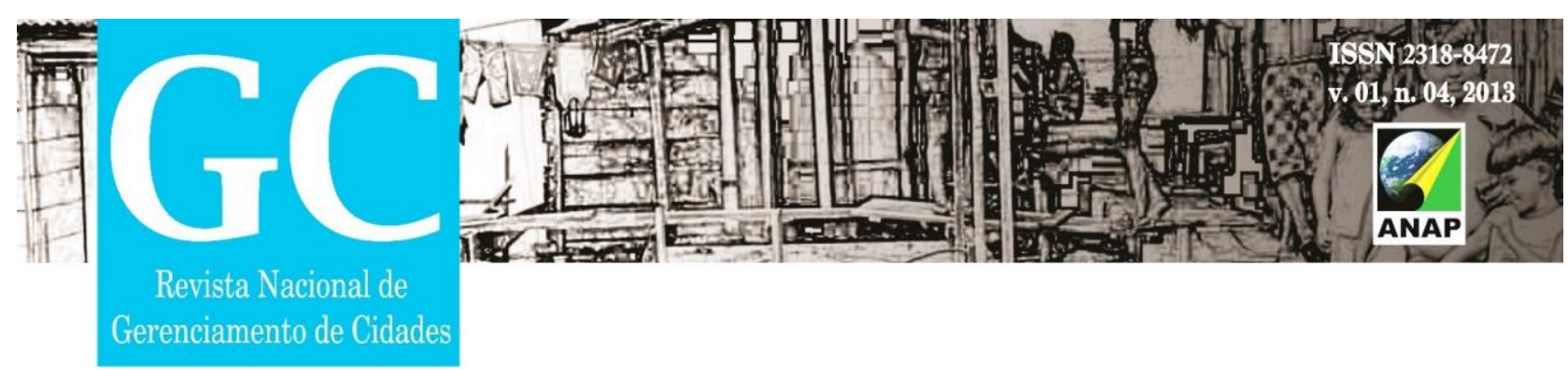

Titulo do Trabalho

\title{
A IMPORTÂNCIA DA PARTICIPAÇÃO DA SOCIEDADE NA DECISÃO URBANA
}

Nome do Autor (a) Principal

Andréa Alves Araújo

Nome do Orientador

Camilo Michalka Jr.

Instituição ou Empresa

Universidade Federal do Rio de Janeiro - UFRJ

Escola Politécnica - POLI

Programa de Engenharia Urbana - PEU

E-mail de contato

andreaaraujo@poli.ufrj.br

Palavras-chave

Desenvolvimento Local. Sustentabilidade urbana. Processo decisório urbano.

1 INTRODUÇÃO

Historicamente, os processos decisórios nas cidades brasileiras se caracterizam pelo predomínio de práticas políticas autoritárias e clientelistas centralizadas no poder executivo e pela representação de interesses particulares em detrimento do interesse coletivo. Tais discrepâncias permanecem, ao longo dos anos, porque existem realidades bastante distintas entre o discurso e a prática. 


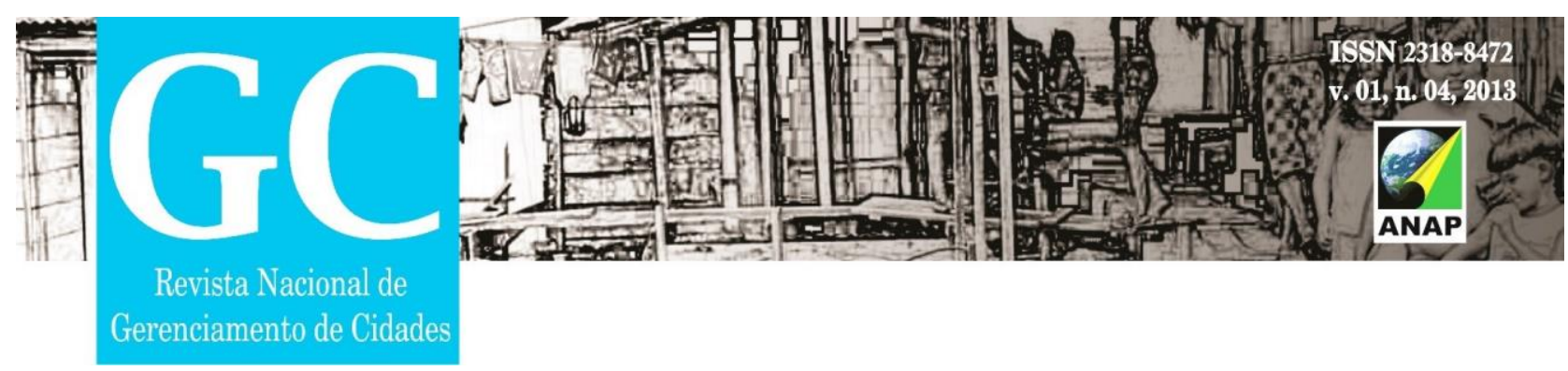

Pelo discurso legal, dois ideais prevalecem: "todo poder emana do povo e em seu nome é exercido"; e "todos são iguais perante a lei, sem distinção de qualquer natureza" . Mas, na prática, a realidade se configura em: "a soberania popular será exercida pelo sufrágio universal e pelo voto direto e secreto"3; e "qualquer cidadão é parte legítima para propor ação popular" ${ }^{\prime 4}$ desde que a iniciativa popular de interesse específico do município, da cidade ou de bairros, por exemplo, seja realizada "através de manifestação de, pelo menos, cinco por cento do eleitorado"5. Ou seja, existem assimetrias entre o desejado e o realizável por um povo que desconhece seus próprios direitos e deveres garantidos por leis também ignoradas.

No Brasil, as políticas e ações em prol do desenvolvimento local ${ }^{6}$ advêm de preceitos instituídos pela Constituição Cidadã $\tilde{a}^{7}$ brasileira, de 1988, regulamentados pelo Estatuto da Cidade $^{8}$ e aplicados às realidades locais por meio de planos diretores ${ }^{9}$ que, em conjunto com outros instrumentos e princípios gerais de política urbana, foram criados para garantir a efetivação dos princípios constitucionais de participação da sociedade ${ }^{10} \mathrm{e}$ de gestão democrática da cidade ${ }^{11}$, assim como, da função social da propriedade ${ }^{12}$ resguardada pelos direitos civis.

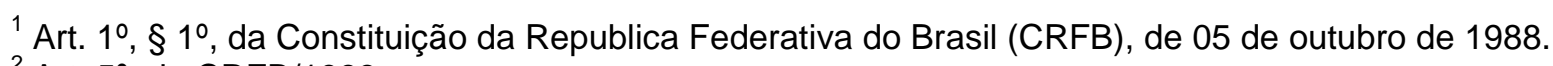

${ }^{2}$ Art. 5o, da CRFB/1988.

${ }^{3}$ Art. 14 da CRFB/1988.

${ }^{4}$ Art. 5o, LXXIII, da CRFB/1988.

${ }^{5}$ Art. 29, XI, da CRFB/1988.

6 O termo "desenvolvimento local", aqui, deve ser entendido como sendo um processo prismático de transformação da realidade local; e não, meramente, econômico.

7 A Carta Magna foi denominada "Cidadã" pelo então presidente da Assembleia Constituinte, o senador Ulisses Guimarães, em discurso proferido, em 27 de julho de 1988, ressaltando o caráter social do texto da Constituinte 1987/1988.

${ }^{8}$ Estatuto da Cidade, Lei Federal № 10.257, de 10 de julho de 2001.

9 Plano Diretor "é o instrumento básico da política de desenvolvimento e expansão urbana" do município (Estatuto da Cidade, art. 40).

${ }_{0}$ CRFB/1988, art. 5ㅇ, LXXIII, dos Direitos e Deveres Individuais e Coletivos; e art. 14, dos Direitos Políticos.

${ }_{11}^{11}$ Artigos 182 e 183 da CRFB/1988.

12 A função social da propriedade encontra-se expressa no art. 1.228, $\S 1^{\circ}$, e nas normas referentes à usucapião, art. 1.238, 1.240 e 1.242 do Novo Código Civil Brasileiro, isto é, da Lei Federal № 10.406, de 10 de janeiro de 2002. (REALE, 2002). 


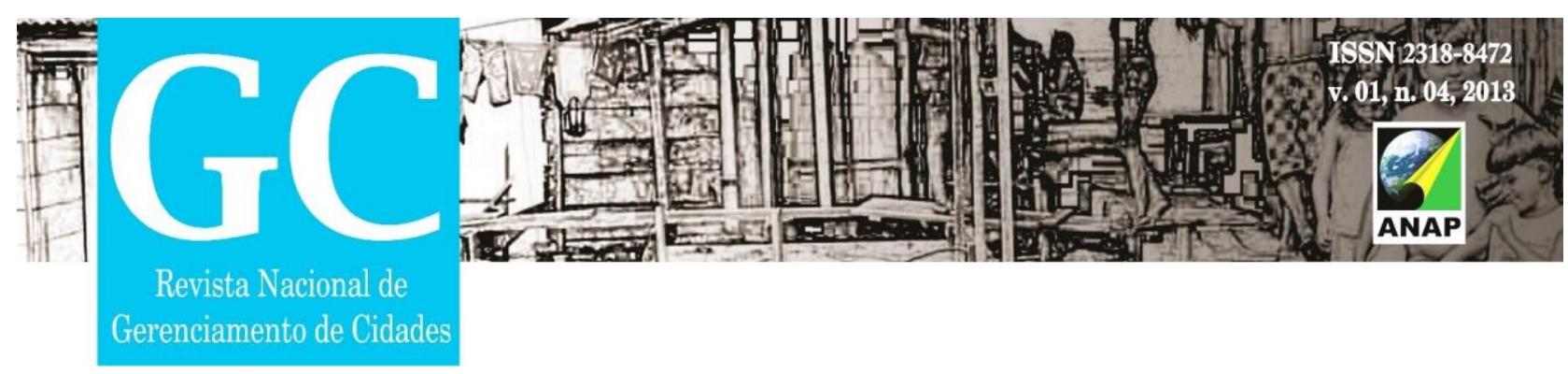

Méritos à parte, o fato é que, até hoje, a efetiva aplicação desses instrumentos de gestão e governança nas políticas urbanas dos municípios brasileiros ainda apresenta distonias que acabam por perseverar problemas, ao invés de ordenar o pleno desenvolvimento das funções sociais da cidade e de garantir o bem-estar de seus habitantes. Há falhas na disseminação e na democratização dos procedimentos. Há fragilidades decorrentes da falta de normatização de práticas e de processos. São debilidades que fazem com que os instrumentos legais não sejam suficientes para assegurar e expandir a participação da sociedade civil brasileira nos processos de tomada de decisão.

A participação é um princípio inerente à democracia, que favorece a qualidade de vida urbana e o atendimento às demandas dos cidadãos. Por conseguinte, os seus procedimentos precisam denotar e constituir significados conhecidos e conscientes para a maioria da população. Ou seja, a falta de participação direta - que é aquela em que os cidadãos não delegam o seu poder de decisão - é uma realidade que precisa ser alterada, pois ter direito às cidades e ao desenvolvimento sustentável ${ }^{13}$ é uma função social urbana, isto é, uma função que se traduz em ter direito à habitação, saúde, saneamento, transporte, educação e a todos os demais serviços e benefícios infraestruturais para as presentes e as futuras gerações.

\section{OBJETIVO GERAL}

O objetivo geral deste trabalho é o de refletir sobre a importância da regularização da participação direta da sociedade em processos de tomada de decisão que visem promover o desenvolvimento sustentável local.

\footnotetext{
${ }^{13} \mathrm{O}$ conceito de "desenvolvimento sustentável" utilizado aqui equivale àquele que "satisfaz as necessidades do presente, sem comprometer a capacidade das gerações futuras de suprir suas próprias necessidades". (WCDE, 1987).
} 


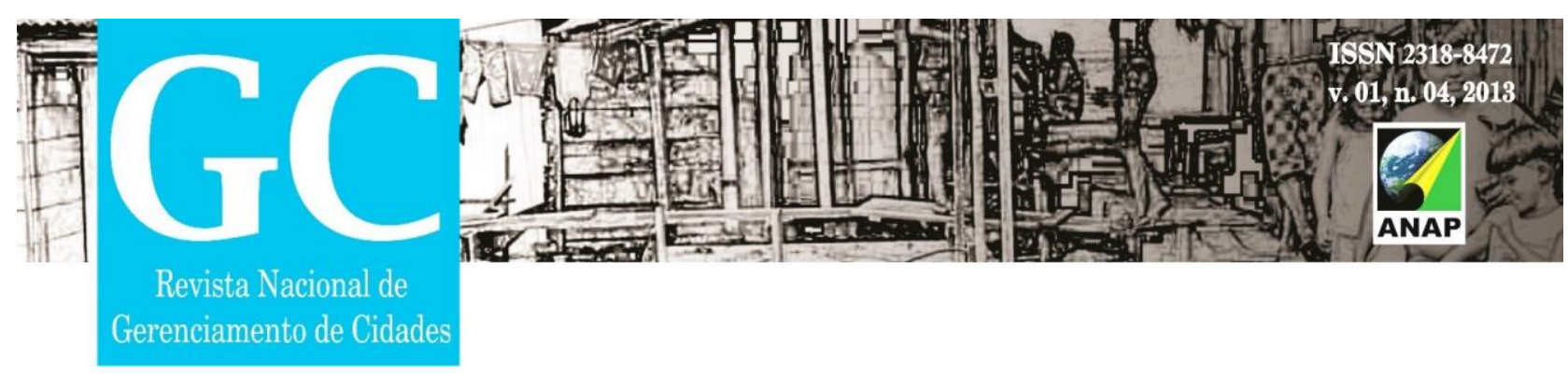

A questão central da pesquisa é: a que medida uma mudança nos padrões de participação da sociedade, nos processos de tomada de decisão local, legitima e promove o desenvolvimento sustentável em um pequeno município?

\section{OBJETIVOS ESPECÍFICOS}

Os objetivos específicos propostos por esta pesquisa são:

i. Refletir sobre a importância da participação da sociedade no processo de tomada de decisão do desenvolvimento sustentável;

ii. Disseminar conceitos e procedimentos legais de iniciativa popular ${ }^{14}$ na tomada de decisão local;

iii. Pontuar os marcos legais relacionados à participação direta nos processos de tomada de decisão;

iv. Propor indicadores e critérios de escolha e de tomada de decisão na construção e no desenvolvimento sustentável de pequenos municípios;

v. Realizar um estudo comparativo entre os instrumentos de participação direta no Brasil e na Alemanha, de modo a destacar a eficácia dos mesmos.

vi. Sugerir uma diretriz para a construção de um modelo de regularização da participação popular ${ }^{15}$ no processo de tomada de decisão local (mecanismos e ferramentas).

vii. Promover a regularização ${ }^{16}$ e disseminar a regulamentação ${ }^{17} \mathrm{da}$ participação direta da sociedade como instrumento essencial para a

\footnotetext{
${ }^{14}$ Aqui, o termo "iniciativa popular" é utilizado como sinônimo de "participação direta".

${ }^{15}$ As expressões "iniciativa popular" e "participação popular" referem-se, aqui, à participação que envolve diversos segmentos sociais nos processos decisórios municipais; e não apenas aos constituídos pelas chamadas "classes populares".

${ }_{17}^{16}$ Regularização é "ato ou ação de regularizar, tornar-se regular, normal ou ordenado" (AULETE DIGITAL, 2013).

17 Regulamentação é o "conjunto de disposições legais concernentes a uma atividade, instituição, etc." (AULETE DIGITAL, 2013).
} 


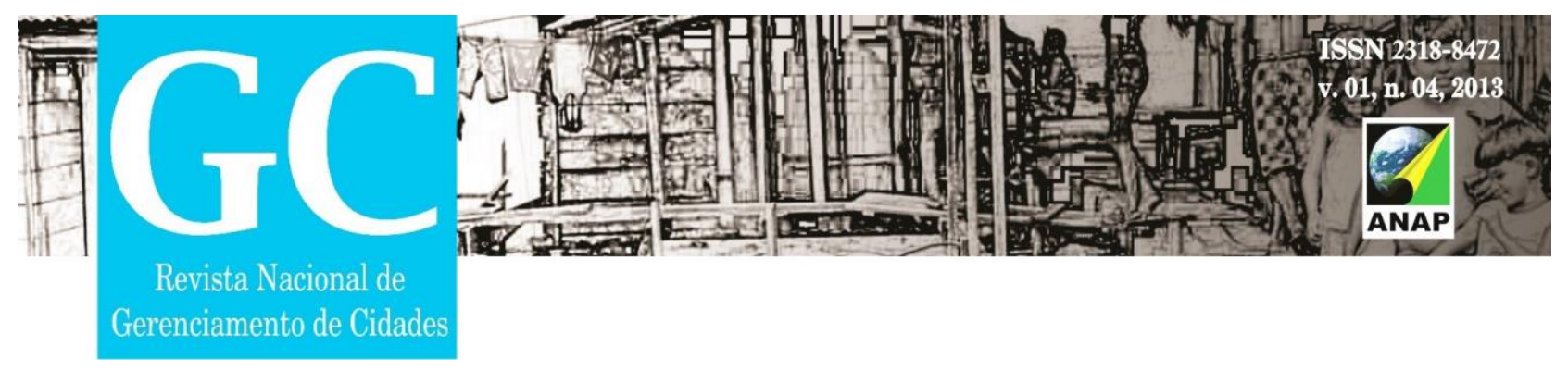

concretização do processo de tomada de decisão que visa 0 desenvolvimento sustentável;

viii. Recomendar parâmetros de mensuração e avaliação da participação da sociedade no processo de tomada de decisão de projetos de desenvolvimento urbano sustentáveis;

\section{METODOLOGIA}

A presente pesquisa encontra-se estruturada em análises comparativas e no exame de possibilidades e limites da participação da sociedade nos processos decisórios urbanos, como instrumento determinante de seu desenvolvimento sustentável local. Trata-se de uma revisão bibliográfica estruturada em estudos exploratórios e comparativos, na definição de parâmetros e no estudo de experiências de projetos urbanos no Brasil e na Alemanha.

\section{RESULTADOS}

Esta pesquisa se justifica na medida em que busca aprofundar o debate científico em torno de um tema ainda pouco desenvolvido no País: a participação direta da sociedade nos processos decisórios urbanos. A relevância de tal assunto provém do desafio lançado pelo Estatuto da Cidade ao incorporar a participação dos cidadãos e das entidades civis nos processos de tomada de decisão municipal, de forma a disseminar e efetivar a participação direta como instrumento de desenvolvimento sustentável local.

Os resultados esperados com esta pesquisa, quanto a parâmetros, regras, indicadores, instrumentos, mecanismos etc., fornecem somente critérios de aparente certeza, já que não existe uma fórmula mágica para se assegurar o desenvolvimento urbano sustentável de uma localidade, seja ela aqui, no Brasil, ou na Alemanha. 


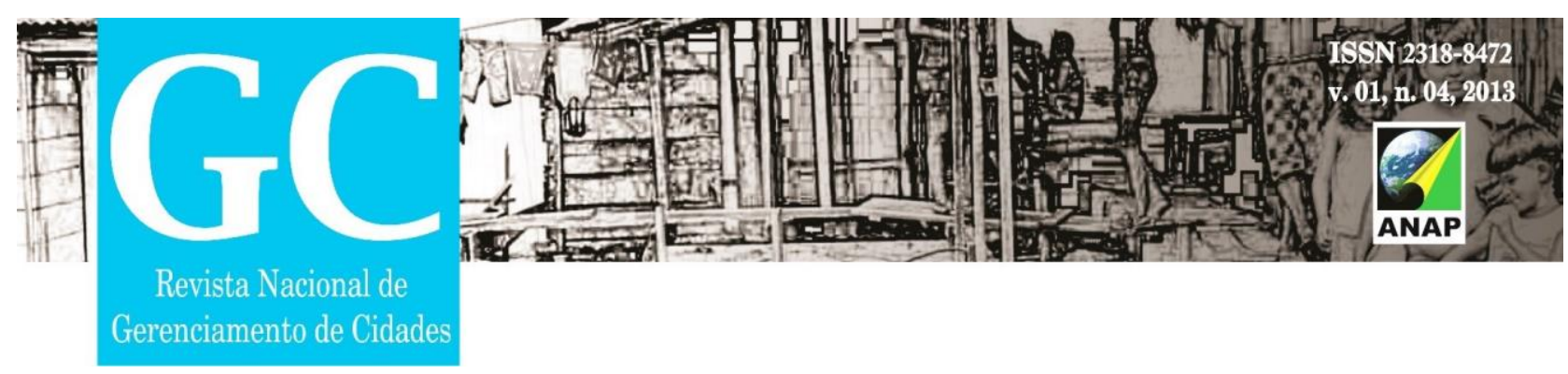

As diretrizes e experiências destacadas aqui servem apenas para construir um novo caminho para se alcançar o desenvolvimento urbano sustentável, de preferência mais sólido, mais rápido e mais conciso, para cada localidade, bairro, município, cidade, estado ou país. Apenas aproveitando as especificidades de cada lugar, momento, espaço.

\section{CONSIDERAÇÕES FINAIS}

A cada dia, cresce a importância de se inserir nos processos decisórios uma parcela maior da sociedade tradicionalmente excluída das decisões estratégicas. Isso ocorre porque a tutela pública está perdendo a atribuída capacidade de ouvir, de entender, de atender e de antever as necessidades dos cidadãos comuns, mesmo com todos os direcionamentos garantidos por lei. Mas, como o processo participativo tende a quebrar as estruturas centralizadas e verticalizadas de decisão e gestão, levando os atores envolvidos a se posicionarem, de forma a participarem das decisões e de se sentirem responsáveis pelas mesmas. Portanto, ao se estabelecer interações entre os diversos atores sociais envolvidos e se suscitar a existência de lacunas entre as demandas locais das populações e as ações do governo, as comparações e os estudos dos casos brasileiro e alemão, agregados às respectivas definições teóricas e legislativas, permitem uma melhor ordenação das fases de construção e de consolidação da iniciativa popular nos processos decisórios e de gestão e de planejamento urbano, principalmente em pequenos municípios. Tais feitos contribuem efetivamente para a ampliação e a democratização dos espaços de negociação da sociedade, além de estimular o envolvimento de todos os envolvidos e o confronto organizado e civilizado de visões e de interesses diversificados. (BUARQUE, 2008, p. 92) 


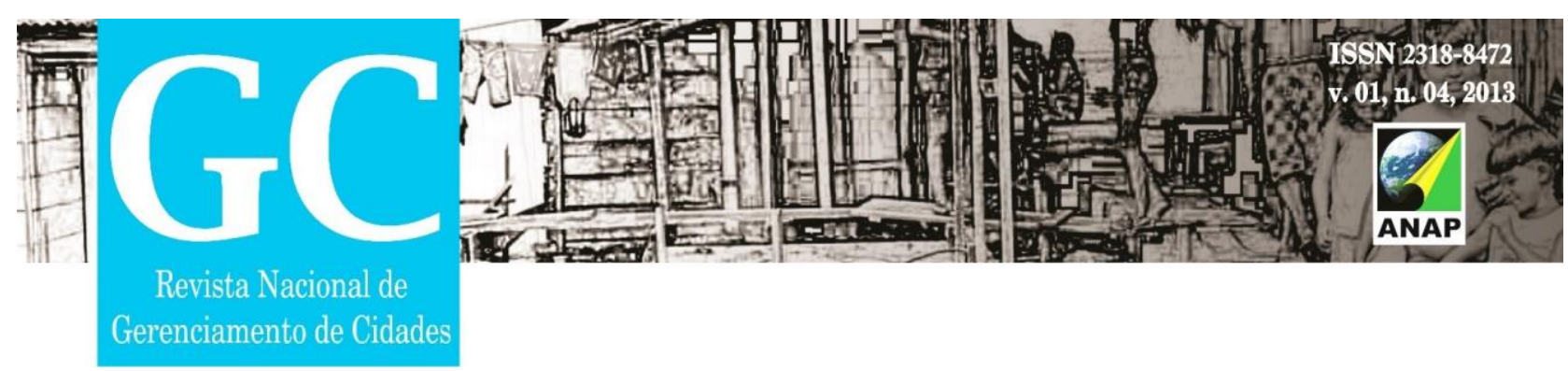

\section{REFERÊNCIAS}

AULETE, A. C. Dicionário Aulete Online. Lexikón Editora Digital, 2013. Disponível em: http://aulete.uol.com.br/site.php?mdl=aulete digital Acesso em: 13 ago. 2013.

BRASIL. Constituição da República Federativa do Brasil [1988]. Brasília, DF: Congresso Nacional, 2013.

BRASIL. Lei no 10.257 [Estatuto da Cidade], de 10 de julho de 2001. Regulamenta os artigos 182 e 183 da Constituição Federal, estabelece diretrizes gerais da política urbana e dá outras providências.

BUARQUE, Sergio C. Construindo o desenvolvimento local sustentável. Rio de Janeiro: Garamond, 2008. 4 ed.

REALE, Miguel. Visão geral do novo Código Civil. Jus Navigandi, Teresina, ano 7, n 54, 1 fev 2002 . Disponível em: http://jus.com.br/revista/texto/2718 . Acesso em: 15 jul. 2013.

WCED. Relatório Brundtland, Report of The World Commission on Environment and Development: Our Common Future, Chapter 2: Towards Sustainable Development, Geneva, Switzerland, ONU, 1987. Disponível em: http://www.un-documents.net/wcedocf.htm . 